\title{
L'ART DE CHANTER ET RIMER \\ POESÍA SANJUANISTA DE ESTILO TERESIANO EN EL CARMELO FEMENINO FRANCO-BELGA
}

DANIEL HANNA

Lake Forest College, Illinois hanna@mx.lakeforest.edu

RESUMEN: En este estudio se presenta y se analiza por primera vez una serie de poemas compuestos en francés por Carmelitas belgas y francesas en los siglos XVIII-XIX. Estos poemas son escritos en el estilo "teresiano", aprovechando melodías de canciones populares, pero celebran, y en un caso imitan, a Juan de la Cruz, creando una poesía carmelitana híbrida que no se ha documento antes. Los poemas manuscritos se han descubierto en los archivos de los conventos de Bruselas y Pontoise (Francia), y representan una aportación importante al estudio de la poesía del Carmelo descalzo y al estudio del impacto de San Juan en Francia. Un breve recuerdo de los poemas de las Carmelitas españolas Cecilia del Nacimiento y María de San Alberto, quienes sacaron tanta inspiración del poema sanjuanista Noche oscura, sirve para establecer el contexto para la presentación de los poemas franco-belgas, en particular un poema que es una adaptación en francés del Cántico espiritual de San Juan. En este poema, el estilo teresiano y el léxico y las imágenes del Cántico sanjuanista se mezclan, en una combinación poética inédita.

PALABRAS CLAVE: Teresa de Jesús; Juan de la Cruz; poesía conventual; cultura transnacional; poesía lírica; traducción. 


\section{L'ART DE CHANTER ET RIMER: Poetry Honoring Juan de la Cruz in the Style of Teresa de Ávila in Franco-Belgian Carmelite Con- vents.}

ABSTRACT: In this study a series of poems written in French by French and Belgian Teresian Carmelites in the 18th and 19th centuries is presented and analyzed for the first time. These poems are written in the "teresian" style, using melodies from popular songs, but they celebrate, and in one case imitate, John of the Cross, creating a hybrid Carmelite poetry which has not been documented before. These manuscript poems were discovered in the archives of the convents of Brussels and Pontoise (France), and represent a significant contribution to the study of poetry in Discalced Carmel, and to the impact of John of the Cross in France. The poems of the Spanish Carmelites Cecilia del Nacimiento and María de San Alberto, who drew so much inspiration from John's poem Noche oscura, serves to establish a context for the presentation of the French and Belgian poems, and in particular one poem that is an adaptation in French of John's Cántico espiritual. In this poem, the teresian style and the lexicon and images of John's Cántico are combined, in an unprecedented poetic combination.

KEY WORDS: Teresa of Avila; John of the Cross; conventual poetry; transnational culture; lyric poetry; translation.

Cabido es que en el Carmelo descalzo fundado por santa Teresa de OJesús en el siglo XVI, la poesía tenía un papel de gran importancia. En más de una ocasión, santa Teresa insistió en que sus hermanas compusieran y compartieran versos ${ }^{1}$ y los poemas que dejaron las Carmelitas de su orden reformada demuestran que el mandato lite-

${ }^{1}$ En sus cartas, Teresa insistió en la importancia de componer coplas y villancicos. Ver sus cartas de 1 de febrero de 1580 y 8 de noviembre de 1581, ambas escritas a María de San José, priora del convento de Sevilla, en Teresa de Jesús, Obras completas, p. 1257 y p. 1352. La práctica de componer y cantar versos formaba parte de las "recreaciones" diarias en el Carmelo descalzo español. Sobre las recreaciones en el Carmelo teresiano, ver María de San José (2002), y sobre la función de los versos y del teatro en la vida conventual, ver Elissa Weaver (2002).

UNED. REI, 3 (2015), pp. 45-80 rario de la santa se respetó. Hoy lo podemos comprobar consultando la edición moderna del Libro de romances y coplas del Carmelo de Valladolid (c. 1590-1609), así como los estudios que se han realizado sobre un cancionero parecido del convento de Medina del Campo ${ }^{2}$, textos que se unen a los que dejó la misma santa Teresa para dar amplia documentación de la tradición poética del Carmelo descalzo femenino en España.

Una serie de estudios recientes ha demostrado que con la expansión del Carmelo descalzo a Francia a principios del siglo XVII, esta tradición se mantuvo: en los conventos de las regiones parisina y borgoñona, las hijas francesas de santa Teresa copiaron tanto el modelo espiritual como el modelo literario de su madre fundadora, componiendo sus propios versos en que celebraron e imitaron a Teresa (Hanna, 2015a, 2015b; y en prensa). Aún más recientemente se ha descubierto una serie de poemas manuscritos en los archivos de los conventos carmelitanos de Pontoise (Francia) y Bruselas cuyo objeto de veneración no es santa Teresa, sino su cofundador y el más célebre poeta del Carmelo descalzo, san Juan de la Cruz. En estos poemas, las carmelitas de Francia y Bélgica mantienen la tradición que inauguró Teresa y al mismo tiempo recuerdan a Juan, demostrando la existencia de un importante legado espiritual y literario a la vez teresiano y sanjuanista dentro del Carmelo descalzo franco-belga. Estas composiciones mezclan elementos teresianos y sanjuanistas de manera novedosa y en un caso de manera aparentemente inédita: uno de los poemas imita el famoso Cántico espiritual de san Juan, creando una poesía híbrida no vista antes, teresiana en estilo y sanjuanista en contenido.

En el presente estudio se presentará y analizará por primera vez esta serie de poemas franco-belgas, considerando primero el ejemplo precursor de la poesía de dos carmelitas españolas que participaron en la tradición teresiana y al mismo tiempo entraron plenamente en el espacio poético sanjuanista.

${ }^{2}$ García de la Concha y Álvarez Pellitero (1982); Álvarez Pellitero (1983: 525-543).

UNED. REI, 3 (2015), pp. 45-80

ISSN 2340-9029 


\section{El precedente español: la presencia sanjuanista en la poesía de dos carmelitas españolas}

Dentro del ya mencionado corpus poético del Carmelo descalzo español de la época de santa Teresa, destacan los poemas de dos autoras, las hermanas espirituales y de sangre Cecilia del Nacimiento (Cecilia Sobrino Morillas, 1570-1646) y María de San Alberto (María Sobrino Morillas, 1568-1640). Los poemas de estas carmelitas españolas han sido analizados en los estudios de Alison Weber, Elizabeth Rhodes, Stacey Schlau, Electa Arenal y Evelyn Toft, entre otros ${ }^{3}$. De especial interés en el contexto de este estudio son las incursiones de estas dos poetas en la noche sanjuanista, es decir, los poemas de ambas hermanas que imitan la famosa Noche oscura de san Juan de la Cruz. En un poema de Cecilia del Nacimiento que aparece bajo el título "Liras de la contemplación sobre la noche oscura", las semejanzas temáticas y estructurales con la Noche sanjuanista son evidentes:

En una noche escura

con ansias en amores inflamada,

¡o dichosa ventura!

salí sin ser notada

estando ya mi casa sosegada.

(Noche oscura, estrofa 1$)^{4}$

$---$

Aquella niebla oscura

es una luz divina, fuerte, hermosa,

inaccesible y pura,

íntima, deleitosa,

un ver a Dios sin vista de otra cosa.

${ }^{3}$ Ver Cecilia del Nacimiento (1970); María de San Alberto y Stacey Schlau (1998); Electa Arenal y Stacey Schlau, (2010: 129-184); Toft (2000: 169-184; 2001: 83-96; 2010: 231-252); Rhodes (2009: 202-217); Weber (2009: 185-201).

${ }^{4}$ La edición de las poesías de san Juan por la que se cita es la de Domingo Ynduráin, en la cual se mantienen algunos aspectos de la ortografía original de los manuscritos sanjuanistas.

La cual a gozar llega

el alma que de amor está inflamada,

y viene a quedar ciega

quedando sin ver nada

la ciencia transcendida y alcanzada.

Y cuando la conquista

del Reino de sí misma es acabada,

se sale sin ser vista

de nadie, ni notada,

la ciencia transcendida y alcanzada.

(Cecilia del Nacimiento, "Liras", estrofas 1-3)

En estas estrofas citadas, una del poema "Noche oscura" de san Juan y tres de las "Liras" atribuidas a Cecilia del Nacimiento, la forma es la misma: la lira, estrofas de cinco versos, tres de siete sílabas y dos endecasílabos. El tema, aunque más explícitamente religioso en el poema de Cecilia del Nacimiento, es muy parecido también: la amante (el alma) que sale "inflamada" en una noche (niebla) oscura "sin ser notada (vista)" en pos de su amante (Dios). María de san Alberto también compuso unas "Liras", muy semejantes a las de su hermana y al poema sanjuanista:

O dulce noche escura

que no pones tiniebla tenebrosa

mas antes tu espesura

cuan ciega es deleytosa

y quanto mas obscura mas hermosa

Divinas negociaciones

Dichosa obscuridad dulce sosiego

secretas inbenciones

dichoso el que es ciego

en tanta claridad dichoso entrego ${ }^{6}$

\footnotetext{
${ }^{5}$ Cecilia del Nacimiento, 1970: 182

${ }^{6}$ María de san Alberto y Stacey Schlau (1998: 236)
}

UNED. REI, 3 (2015), pp. 45-80

ISSN 2340-9029 
En estas estrofas, en vez de entrar en una "niebla oscura", la poeta se adentra en una "noche oscura" plenamente sanjuanista. Las "divinas negociaciones" y "secretas invenciones" que se evocan en la segunda estrofa recuerdan el carácter clandestino de la segunda del poema de san Juan:

\section{Ascuras y segura}

por la secreta escala, disfraçada,

¡o dichosa ventura!

a escuras y en celada

estando ya mi casa sosegada. (Noche oscura, estrofa 2)

Estos poemas de Cecilia del Nacimiento y María de San Alberto rinden homenaje, tanto en la forma como en el tema, a Juan de la Cruz a la vez que son poemas que pertenecen de manera general a la tradición de poesía conventual en la que insistió Teresa de Jesús. Hasta cierto punto por lo menos, se podría decir que en el Carmelo descalzo español, existe una poesía que es sanjuanista y teresiana a la vez. En las páginas que siguen se verá que se puede decir lo mismo, quizás con más certeza, del Carmelo descalzo franco-belga de los siglos posteriores a la expansión de la orden al norte de los Pirineos.

\section{El eco franco-belga: Bélgica}

En el año 1842, dos siglos después de que las hermanas Cecilia del Nacimiento y María de San Alberto compusieran sus poemas inspirados por la Noche oscura de san Juan de la Cruz, las Carmelitas de Bruselas celebraban el 250 aniversario de la muerte del santo. Una de ellas, Marie-Joseph de Jésus, conmemoró la ocasión en un poema titulado "Couplets composés à l'occasion du jubilé de 250 de la mort de notre père St Jean de la Croix"7. Mientras que Cecilia del Nacimiento y María de San Alberto habían compuesto "liras" sanjuanistas, imitando la forma estrófica culta del poema de san Juan, Marie-Joseph

${ }^{7}$ Este poema aparece en un volumen titulado Cantiques spirituels du Carmel de Bruxelles, y que se encuentra en los archivos del convento de Carmelitas descalzas de Bruselas. El volumen es de 128 páginas, y contiene 42 poemas. No todos los poemas contienen fechas, pero los que sí las contienen son todos del siglo XIX. de Jésus eligió un modelo métrico más bien popular. Así, en vez de componer su homenaje a san Juan en versos alejandrinos dodecasílabos - la forma métrica más favorecida en la poesía culta de su época-, Marie-Joseph aprovechó una canción popular como modelo métrico y melódico: en el manuscrito que contiene su poema, precede la primera estrofa la siguiente indicación: "Air : Rien n'est égal à mon bonheur". Presuntamente el título (o quizás el estribillo) de una canción de la épocas ${ }^{8}$ el verso octosilábico "Rien n’est égal à mon bonheur", proporciona el patrón métrico para el poema de Marie-Joseph de Jésus. En este aspecto su poema parece seguir lo que Antonio Prieto identifica como "la pauta teresiana" de "villancicos y coplas a lo divino" (Orozco Díaz, 1994: I, 582), es decir, la práctica de componer versos espirituales que se podían cantar sobre melodías derivadas de canciones populares que era típica en el Carmelo descalzo español. Se sabe, por ejemplo, que el famoso poema de santa Teresa Muero porque no muero tenía antecedentes populares (García de la Concha, $1978,332-41)$ y se cree que otras carmelitas de la época de Teresa también componían letras “a lo divino” que se podían cantar sobre melodías conocidas. Como explica Víctor García de la Concha, "Lo habitual en los palomarcicos teresianos era, pues, lo más popular, la trasmutación de lo que andaba en boca de las gentes "no curiosas"' (García de la Concha y Álvarez Pellitero, 1982, xlvii). En el Carmelo descalzo franco-belga, este hábito se mantuvo: casi todos los poemas en los manuscritos que se han hallado en archivos carmelitanos en Francia y Bélgica vienen acompañados de una indicación melódica y en la mayoría de los casos se trata de melodías de canciones populares de la época. Esta preferencia por formas métricas populares en vez de versos de arte mayor (como las liras italianas-españolas o los alejandrinos franceses) es un rasgo fundamental de la poesía femenina del Carmelo franco-belga. Como tal, en términos no solo de tradición

${ }^{8}$ No se ha encontrado ninguna canción de la época con este título, pero existen varias canciones que contienen el verso "Rien n'est égal à mon bonheur", por ejemplo la siguiente, de la octava escena de la obra teatral Le Dîner sur l'herbe de Eugène Scribe (1824): "Quel doux espoir à mes yeux brille !/ Je ne suis plus de la famille ;/ Je suis le maître de mon cœur :/ Rien n'est égal à mon bonheur" (Scribe, 1824: 31).

UNED. REI, 3 (2015), pp. 45-80

ISSN 2340-9029 
sino también de estructura, estos poemas se pueden considerar como típicamente teresianos y el poema de Marie-Joseph de Jésus no es una excepción ${ }^{9}$. Al mismo tiempo, como se verá más adelante, el poema de Marie-Joseph tiene una vena sanjuanista importante, recordando los papeles histórico y literario del santo en el Carmelo descalzo.

\section{Alabanza a san Juan}

El tono de elogio que se establece en el título del poema se reafirma en los primeros versos:

Pour célébrer votre victoire

Digne Père Jean de la Croix

Des saints habitants de la gloire

Que n'ai-je aujourd'hui la voix... ${ }^{10}$

Dirigiéndose directamente a Juan de la Cruz, Marie-Joseph de Jésus evoca en la primera estrofa la "victoria" del santo y también su "dignidad"; en otros pasajes del poema lo trata de "intrépide et courageux" (estrofa 3), y menciona su "ferveur" (estrofa 4) y su "âme généreuse" (estrofa 6). Como alabanza general del santo, el poema cumple con lo que el título parece prometer. Pero más allá de su función encomiástica, este poema tiene (por lo menos) dos propósitos

${ }^{9}$ Cabe recordar que san Juan de la Cruz también compuso poemas "a lo divino". Se podría citar como ejemplo su versión de "Muero porque no muero", la cual se confundió con la de Teresa durante muchos años, y sus poemas "Tras de un amoroso lance" y "Por toda la hermosura", que en la edición de Domingo Ynduráin se identifican como glosas "a lo divino" (Ynduráin 267-76). Lo que planteamos en este estudio es la coexistencia de dos estilos: un estilo de poesía típicamente teresiano, basado en canciones populares, y también un estilo que se suele asociar con san Juan, el estilo culto de sus grandes poemas Cántico espiritual, Noche oscura y Llama de amor viva. Se verá que en los poemas de las Carmelitas de Francia y Bélgica, sobre todo en el poema que se presenta al final de este artículo, se trata de una combinación de estilo teresiano y temas, imágenes y léxico sanjuanistas.

${ }^{10}$ Marie-Joseph de Jésus, "Couplets composés à l'occasion du jubilé de 250 de la mort de notre père St Jean de la Croix", estrofa 1. más: recordar la "historia familiar" del Carmelo descalzo y la fama literaria del que fue su cofundador.

\section{Historia familiar - la reforma teresiana}

En la tercera estrofa de su poema, Marie-Joseph de Jésus relata cómo Juan de la Cruz tomó la decisión de hacerse carmelita descalzo en vez de cartujo. Se cuenta que la austeridad de los cartujos atraía al joven carmelita, pero que Teresa de Jesús lo convenció a participar en su reforma (Pérez, 2007: 167). Marie-Joseph lo recuerda así:

\section{Je vous vois Bienheureux Père \\ Intrépide et courageux \\ Méditer une vie plus austère \\ Jeter les yeux sur les Chartreux. \\ Mais la sagesse éternelle \\ A sur vous bien d'autres desseins \\ Et d'une réforme nouvelle \\ Vous serez l'appui, le soutien. ${ }^{11}$}

En la estrofa siguiente, Marie-Joseph recuerda que la reforma en la que Juan de la Cruz asistió a Teresa de Jesús tenía por objetivo el retorno a la primera regla de la Orden de Nuestra Señora del Monte Carmelo y cómo Teresa valoraba el fervor con el cual su joven asistente participó en la realización de este objetivo:
Ce fut l'observance première
Qui vous captiva le cour
Et notre séraphique Mère
Sut bien priser votre ferveur
Le but de cette entreprise
Fut surtout la gloire de Dieu
L'exaltation de son Église

Former des saints en tous les lieux. ${ }^{12}$

\footnotetext{
${ }^{11}$ Ibidem, estrofa 3.

${ }^{12}$ Ibidem, estrofa 4.

UNED. REI, 3 (2015), pp. 45-80
}

ISSN 2340-9029 
La última estrofa del poema es nada menos que una oración a san Juan en que la carmelita belga pide que el convento de Bruselas sea una copia espiritual del monasterio que Juan había fundado en Duruelo (en la provincia de Segovia) casi tres siglos antes, en 1568:

Obtenez $\mathrm{O}$ notre saint Père

Que tout le Carmel réformé

Soit une heureuse pépinière

En vertus et en sainteté

Et que ce couvent de Bruxelles

Par une noble émulation

De la ferveur de Durxelle

Soit une vive expression. ${ }^{13}$

Para las Carmelitas de Bruselas, la memoria de san Juan seguía viva en el siglo XIX, por sus cualidades generales (su dignidad, su fervor, la generosidad de su alma) y también por el importante papel que había tenido en la formación del Carmelo descalzo, cuyos detalles Marie-Joseph de Jésus recordaba en su poema: la decisión del santo de unirse a Teresa de Jesús en la reforma de la orden, la atracción que ejercía sobre él la regla primitiva del Carmelo y la fundación que hizo en Duruelo, que Marie-Joseph concebía como modelo para su propio convento. ${ }^{14}$ Pero esta celebración del padre del Carmelo descalzo no

\section{${ }^{13}$ Ibidem, estrofa 8.}

${ }^{14}$ El hecho de citar el monasterio de Duruelo como modelo para el convento de Bruselas suscita la cuestión del grado ideal de rigor y austeridad en el Carmelo teresiano. Se sabe, por ejemplo, que los Carmelitas de Duruelo practicaban penitencias especialmente severas, pero que Teresa les pidió a los frailes que suavizaran algo estas mortificaciones. En los archivos del convento de Pontoise, he encontrado documentos manuscritos que indican que la cuestión general de la austeridad también se debatió en los conventos franceses de los siglos XVII-XVIII. En sus cartas, Madeleine de Saint-Joseph (1578-1635), la primera priora en el Carmelo teresiano francés, explica cómo el cardenal Pierre de Bérulle había reducido las "licencias" (licences), diciendo que, respecto a estos momentos de relajamiento de las reglas estrictas del convento, "[Bérulle] ne croyait point non plus que nous que cette coutume vînt de sainte Thérèse et qu'il la tenait bien plus propre à divertir les esprits et à les dissiper qu'à augmenter la dévotion" (Madeleine de Saint-Joseph 1965: carta CCXI). En un texto manuscrito de los archivos del convento de Saint-Denis (que hoy se hallan en Pontoise), titulado se limitó al elogio general e historia familiar: como se ve en las primeras estrofas, lo que recordaba Marie-Joseph en su poema -antes aún de recordar su importancia en la reforma teresiana- era su fama literaria.

\section{"Au défaut de l'éloquence"}

Ya se ha visto cómo, en los primeros versos de la primera estrofa del poema, Marie-Joseph evoca la "victoria" y la "dignidad" de Juan de la Cruz. Pero en los versos que siguen, antes de pasar a elogiar las cualidades del santo y su participación en la reforma teresiana, Marie-Joseph se detiene para dejar claro que su propia capacidad poética no es comparable a la de san Juan:

Pour célébrer votre victoire

Digne Père Jean de la Croix

Des saints habitants de la gloire

Que n'ai-je aujourd'hui la voix

Ma très profonde ignorance

Des licences, ou des grandes récréations, leemos: "Quoique la Règle et les Constitutions ne fassent aucune mention des licences, l'usage primitif, et général qui est le meilleur interprète des lois; ne permet pas de douter que Notre Sainte Mère Thérèse n'en ait accordé quelques unes. En effet s'il est aisé de marquer le temps où certains de nos monastères du Royaume ont aboli les licences qui y subsistaient auparavant, on ne saurait dire quand elles y ont commencé, ce qui est une preuve indubitable que leur origine est la fondation même des couvents, que c'est par conséquent à nos Mères Espagnoles qu'on doit en attribuer l'usage et par conséquent que cet usage était conforme à l'esprit, et à la pratique de Sainte Thérèse" (cursiva añadida) (Des licences, ou les Grandes Récréations; en Réfléxions et insructions sur les principaux devoirs de notre saint état, pp. 7-11. Archivos del convento de Pontoise, Francia, 7). Estos documentos indican que, como en la época de santa Teresa y san Juan, en los primeros siglos del Carmelo teresiano francés no había unanimidad en cuanto a la cuestión general del rigor. Se podría suponer que la cuestión también hubiera sido importante para las Carmelitas belgas del siglo XIX, pero hasta qué punto el poema de Marie-Joseph de Jésus formaría parte de algún debate más general sobre el tema sólo se podrá confirmar con investigaciones más profundas de los archivos conventuales belgas.

UNED. REI, 3 (2015), pp. 45-80

ISSN 2340-9029 
Dans l'art de chanter et rimer

Implore votre indulgence

Me veuillez bien la pardonner. ${ }^{15}$

$\mathrm{Al}$ declararse incapaz de "chanter et rimer", Marie-Joseph de Jésus hace un gesto doblemente teresiano, refiriéndose a la tradición teresiana de poesía cantada en la que su poema se inscribe, y también adoptando una postura de humilitas semejante a la de Teresa, quien escribió sobre sus propias capacidades poéticas: "Yo sé persona que, con no ser poeta, que le acaecía hacer de presto coplas muy sentidas declarando su pena bien"16, proclamando la sinceridad de sus versos sin calificarlos de "poesía" ${ }^{17}$. Al mismo tiempo, la autocrítica literaria de Marie-Joseph de Jésus evoca el considerable estatus literario de Juan de la Cruz. Se ve que, consciente de que un homenaje en versos a san Juan era a la vez laudatorio y algo audaz dada la inmensa fama literaria (sobre todo poética) del santo, la madre Marie-Joseph sintió la necesidad, ya en la primera estrofa, de pedirle perdón (de manera particularmente teresiana) por no estar a la altura de las circunstancias literarias. Es de notar, además, que la deficiencia a la que se refiere Marie-Joseph es literaria-creativa y no necesariamente espiritual. La segunda estrofa lo deja claro:

Au défaut de l'éloquence

Puisse-je offrir les vertus ;

L'humilité, l'obéissance,

Un amour tendre pour Jésus,

Et puis cette soif si ardente

Qui vous fit tout apprécier

\footnotetext{
${ }^{15}$ Marie-Joseph de Jésus, "Couplets composés à l’occasion du jubilé de 250 de la mort de notre père St Jean de la Croix", estrofa 1.

${ }^{16}$ Teresa de Jesús (2006: 94).

${ }^{17}$ En Teresa of Avila and the Rhetoric of Femininity, Alison Weber demuestra que una de las principales estrategias retóricas de santa Teresa era precisamente un tipo de humilitas femenina, y que Teresa aprovechó esta técnica para comunicar sus ideas sin provocar la crítica de sus superiores masculinos.
}

Si pris de vos croix très pesantes

Que vous eûtes à supporter. ${ }^{18}$

Capaz quizás de imitar a san Juan en términos de virtudes - humildad, obediencia, amor por Jesús - Marie-Joseph pide perdón desde los primeros versos por no ser mejor poeta y aunque no lo dice de manera explícita, las excusas que da la carmelita se pueden interpretar como el reconocimiento de la grandeza poética del objeto de su elogio. Estas disculpas también se pueden leer como el reconocimiento de que rezar a san Juan con un poema era el mayor encomio que se pudiera hacer a su grandeza poética y al mismo tiempo un acto literario altamente osado. Se verá ahora que las Carmelitas de Francia también recordaban a Juan de la Cruz con poesía de estilo teresiano, pero con algunas diferencias importantes, sobre todo en su manera de mezclar homenaje e imitación.

\section{El eco franco-belga: París y Pontoise}

En los archivos del convento de Pontoise, ciudad situada a unos treinta kilómetros al norte de París, se han descubierto varios poemas manuscritos, entre ellos una serie de seis poemas que celebran a san Juan de la Cruz ${ }^{19}$, esta vez no con ocasión del aniversario de su muerte, sino para celebrar el 24 de noviembre, día de su festividad ${ }^{20}$. A diferencia del poema de Bruselas, los poemas en los archivos de Pontoise carecen de fechas de composición o de atribuciones de autoría, pero como todos llevan el mismo título - "Pour la fête de notre père Saint Jean de la Croix"- que se refiere a Juan de la Cruz como

${ }^{18}$ Marie-Joseph de Jésus, "Couplets composés à l'occasion du jubilé de 250 de la mort de notre père St Jean de la Croix", estrofa 2.

${ }^{19}$ Estos poemas aparecen en un volumen sin título ni fecha que se encuentra en los archivos del convento de Carmelitas descalzas de Pontoise. De 423 páginas, el volumen contiene cientos de poemas con una gran variedad de temas, entre ellos la serie de seis poemas celebrando a san Juan de la Cruz.

${ }^{20}$ Con la reforma del calendario romano de 1969, el día de la festividad de san Juan cambió al 14 de diciembre, pero en la época en que se compusieron los poemas de Pontoise, el día del santo era el 24 de noviembre. 
santo y hace referencia a su "fête", es decir el día en que se celebra su festividad, se puede suponer que la fecha de composición de los poemas es posterior a 1726, el año en que Juan de la Cruz fue canonizado.

Aunque hoy estos poemas se encuentran en los archivos del convento de Pontoise, parece que venían por los menos de dos casas diferentes: tres de los seis poemas están precedidos en el manuscrito por la indicación "de Pontoise", y dos están precedidos por "de Grenelle”, referencia al convento que de 1689 a 1790 existía en la calle parisina rue de Grenelle(Béraud, 1828, Tome I: 127). Con estos datos, podemos reducir a un intervalo de unos sesenta años las fechas probables de composición de los poemas de Grenelle (entre 1726, fecha de la canonización de san Juan, y 1790). Como el convento de Pontoise lleva desde su fundación en 1605 ocupando el mismo lugar (55 rue Pierre Butin), la datación de los poemas atribuidos a este convento es más difícil, como lo es la datación del primero de los seis poemas, que no lleva indicación alguna de la fecha de composición, su autoría o procedencia. Dicho esto, los seis poemas parecen haber sido copiados por la misma mano y, como se encuentran todos en el mismo volumen, es razonable plantear que este primer poema sea, como los demás, de un convento carmelitano, de Pontoise, de rue de Grenelle, o de otro.

Como el poema de Bruselas antes citado, los seis poemas de los archivos de Pontoise siguen la tendencia teresiana: en vez de imitar la poesía culta de su época, tienen por modelo métrico y melódico canciones populares, algunas profanas, otras sacras: “Toute la nuit j'ai la puce à l'oreille" (poema 1, sin atribución), "Je suis la simple violette" (poema 2, de Pontoise), "Bel astre que j’adore” (poema 3, de Pontoise), "Vous brillez seule en ces retraites" (poema 4, de Pontoise), "C'est Dieu que nous devons suivre" (poema 5, de Grenelle), y "Amateurs des biens périssables" (poema 6, de Grenelle). Al igual que en el poema de Bruselas, en estos poemas estilísticamente teresianos se pueden leer elogios a san Juan, elementos de la historia del Carmelo descalzo, referencias a la elocuencia del santo y en un caso muy especial, la imitación del famoso Cántico espiritual sanjuanista.

\section{Alabanza a san Juan}

Como lo hace Marie-Joseph de Jésus en la primera estrofa de su poema, la autora del primero de los seis poemas de la serie de Pontoise empieza su elogio a san Juan con una referencia a la tradición teresiana, invitando a sus hermanas a participar en una alabanza colectiva cantada:

Chantons mes sœurs aujourd'hui la mémoire

du St trépas de l'éclatante gloire

que mérita le grand Jean de la Croix

en son honneur réunissons nos voix

réunissons nos voix. ${ }^{21}$

En la primera estrofa del segundo poema de la serie, se compara al padre del Carmelo descalzo con el padre del Carmelo original. La autora trata a san Juan de "nuevo Elías", comparándolo al profeta que inspiró la fundación de la Orden de los Carmelitas en el Monte Carmelo en Israel en el siglo XII:

\section{Rendons un hommage sincère \\ Au nouvel Elie du Carmel \\ Il attira sur cette terre \\ D’abondantes pluies du ciel... ${ }^{22}$}

La primera estrofa del tercer poema de la serie recuerda el tono de disculpa del poema de Bruselas. Así como Marie-Joseph de Jésus, la autora de este poema empieza su celebración de san Juan con una referencia al canto y con humilitas, lamentando las "voces" inadecuadas de la comunidad:

\section{Pour chanter les louanges \\ de St Jean de la Croix \\ que n'avons-nous des anges \\ les concerts et les voix... ${ }^{23}$}

21 "Pour la fête de notre père Saint Jean de la Croix", Poema 1, estrofa 1.
22 "Pour la fête de notre père Saint Jean de la Croix", Poema 2, estrofa 1.
23 "Pour la fête de notre père Saint Jean de la Croix", Poema 3, estrofa 1.

UNED. REI, 3 (2015), pp. 45-80

ISSN 2340-9029 
En la primera estrofa del cuarto poema, el santo es nada menos que un "milagro de amor":

Quel est ce ravissant spectacle

qu'offre à nos yeux la fête de ce jour

Jean de la Croix ce beau miracle

de plus pur (bis) et parfait amour $?^{24}$

La autora del quinto poema empieza su elogio a san Juan con un toque de humor, y al mismo tiempo exhibe un conocimiento de la doctrina sanjuanista y su énfasis en la "nada" espiritual ${ }^{25}$ :

Le démon a dit lui-même

que Jean lui ravit son bien

en apprenant, Seigneur, au cœur qui t'aime

qu'il doit marcher par le sentier du rien... ${ }^{26}$

En el último poema de la serie, san Juan es "el amante de las cruces", y se maravilla que hasta los sufrimientos del amor divino sean dulces:

L'amant des croix au milieu de ses chaînes

Dit à Jésus, l'objet de ses désirs :

«Si votre amour est si doux dans les peines

Hélas ! qu'est-ce donc que ses plaisirs?»

« Je vis en paix au milieu des alarmes

mon cœur s'y plaît dans ses tristes soupirs

si dans vos maux vous mêlez tant de charmes

Hélas ! qu'est-ce donc que ses plaisirs ? ${ }^{27}$

24 "Pour la fête de notre père Saint Jean de la Croix", Poema 4, estrofa 1.

${ }^{25}$ En su artículo "Poética de 'nada' según san Juan de la Cruz" Bernard Sesé (2005) explora la "nada sanjuanista" tal y como se manifiesta en las obras del santo, citando por ejemplo el gráfico de la Subida del Monte Carmelo que dibujó san Juan y en que se leen estas palabras: "Nada, nada, nada...y aún en el monte nada". Quizás a esta frase se refiere la autora del poema de rue de Grenelle cuando escribe ...il doit marcher par le sentier du rien.

26 "Pour la fête de notre père Saint Jean de la Croix", Poema 5, estrofa 1.

27 "Pour la fête de notre père Saint Jean de la Croix", Poema 6, estrofas 1-2.
Este breve vistazo a las primeras estrofas de los seis poemas de la serie de los archivos de Pontoise es suficiente para demostrar que las Carmelitas de Pontoise y de rue de Grenelle celebraban a san Juan de manera teresiana con canciones colectivas, y que lo hacían con consciencia de los orígenes de su orden, con conocimiento de la doctrina sanjuanista, con humildad y hasta con humor. Se verá ahora que, como Marie-Joseph de Jésus en Bruselas, las Carmelitas de la región parisina también recordaban en sus poemas el papel del santo en la fundación del Carmelo descalzo.

\section{Historia familiar - la reforma teresiana}

Al igual que en el poema de Bruselas, en los tres atribuidos al convento de Pontoise se hace referencia a san Juan como cofundador del Carmelo descalzo. En la primera estrofa del segundo poema de la serie, en que se trata al Carmelita de "nuevo Elías", también se lo califica del "padre de familia" que hizo posible una rica cosecha espiritual en tierra “infértil”, quizás una referencia al Carmelo antes de la reforma teresiana en España o más probablemente una referencia a Francia, donde en el siglo XVII el Carmelo descalzo, entre otras órdenes reformadas, había vigorizado el Catolicismo después de las guerras de religión del siglo XVI ${ }^{28}$ :

Rendons un hommage sincère

Au nouvel Elie du Carmel

Il attira sur cette terre

D'abondantes pluies du ciel

Qui couvrent de moissons le champ

Depuis longtemps stérile

Qui couvrent de moissons le champ

Du père de famille. ${ }^{29}$

\footnotetext{
28 Torres Sánchez (2000: 17-87).

29 "Pour la fête de notre père Saint Jean de la Croix", Poema 2, estrofa 1.
}

UNED. REI, 3 (2015), pp. 45-80

ISSN 2340-9029 
El tercer poema detalla más el papel que tuvo san Juan en la reforma carmelitana, con referencias a su relación con santa Teresa y, como en el poema de Bruselas, una mención del monasterio de Duruelo:

\section{De la grande Thérèse \\ Il est le fils aîné \\ Cette grande maîtresse \\ Nous l'a jadis donné. \\ Son premier exercice \\ Fut à Durvel \\ Commençant l'édifice \\ Du beau Carmel. ${ }^{30}$}

Christopher C. Wilson (2007: 134-166) ha demostrado que en los años anteriores a su canonización en 1726, las representaciones visuales de Juan de la Cruz daban progresivamente más importancia a su papel como co-reformador, otorgándole así un estatus de paterfamilias del Carmelo reformado que, según algunos, no corresponde a su verdadera contribución - importante pero limitada - a dicha reforma.Por su parte, las Carmelitas de Francia parecen tener claro que aunque sea el père de famille, Juan sigue siendo el "hijo" (le fils aîné) y Teresa sigue siendo la grande maîtresse. Por una parte, entonces, las Carmelitas francesas parecen haber heredado la imagen de Juan como el padre de su orden; por otra parte, aunque este tercer poema de la serie sea, como los demás, un homenaje a Juan, en la estrofa citada arriba se reconoce claramente a Teresa como superior a su "hijo" espiritual, y se deja claro que fue Teresa quien "creó", en cierto sentido, a Juan: Cette grande maîtresse/Nous la jadis donné.

En el cuarto poema, en que se describe a san Juan como "bello milagro", las Carmelitas de Pontoise celebran su presencia en "nuestra tierra", muy probablemente otro recuerdo de los orígenes españoles del Carmelo descalzo y de su expansión a Francia al principio del siglo XVII:

\section{0 "Pour la fête de notre père Saint Jean de la Croix", Poema 3, estrofa 4.}

Célébrons-le dans notre terre

N'oublions pas un autre dont le cours

Lui fut jadis si salutaire

Qu'elle en est (bis) heureuse en nos jours. ${ }^{31}$

En estos poemas de carácter teresiano el elogio de san Juan recuerda no solamente su participación en la reforma del Carmelo español, sino también el impacto y el beneficio de esa reforma en Francia, con la expansión del Carmelo descalzo al norte de los Pirineos. Y si las Carmelitas de Francia celebraban al santo por su contribución a la reforma teresiana y a la expansión que resultó de esa reforma después de su muerte, también celebraban las capacidades poéticas de san Juan, evocando como Marie-Joseph de Jésus de Bruselas su propia falta de elocuencia.

\section{"Au défaut de l'éloquence"}

Al igual que Marie-Joseph de Jésus en Bruselas, las Carmelitas de Pontoise eran conscientes de la elocuencia necesaria para elogiar al que a sus ojos fue, con santa Teresa, un fundador del Carmelo descalzo y, como Teresa, un gran escritor. Ya se ha mencionado cómo en el tercer poema de la serie de los archivos de Pontoise, las Carmelitas francesas manifestaron el deseo de cantar con "voces" mejores, más aptas para la alabanza de san Juan:

\section{Pour chanter les louanges \\ de St Jean de la Croix \\ que n'avons-nous des anges \\ les concerts et les voix... ${ }^{32}$}

En el segundo poema de la serie, en que Juan de la Cruz es un "nuevo Elías" y el "padre de familia", la autora pregunta (siempre con

31 "Pour la fête de notre père Saint Jean de la Croix", Poema 4, estrofa 2.
32 "Pour la fête de notre père Saint Jean de la Croix", Poema 3, estrofa 1.

UNED. REI, 3 (2015), pp. 45-80

ISSN 2340-9029 
una humilitas que recuerda la de Teresa) qué pluma estaría a la altura de describir el amor del santo:

Quelle est la plume assez fidèle

Pour tracer cet amour divin?

Il faudrait la tirer de l'aile

Du plus embrasé séraphin... ${ }^{33}$

Cabe reiterar que la deficiencia a la que se alude en los dos poemas de Pontoise citados arriba y en el poema de Marie-Joseph de Jésus de Bruselas es de orden poético y no necesariamente espiritual. La voz y la pluma que les faltan a las Carmelitas franco-belgas en el momento de elogiar a san Juan son instrumentos de expresión que les permitirían emular a su padre, no solamente en el aspecto espiritual sino también en el literario. Pero hasta ahora, las hijas franco-belgas de Juan de la Cruz parecen haber limitado el elogio del santo a la alabanza de sus virtudes, su contribución a la reforma teresiana y su elocuencia, sin intentar reproducir esa elocuencia en sus propios versos. Como escribe Marie-Joseph de Jésus, "Au défaut de léloquence/ puisse-je offrir les vertus/l'humilité, l'obéissance/un amour tendre pour Jésus" ${ }^{34}$, dejando claro que está dispuesta para imitar las virtudes de san Juan, pero no necesariamente su poesía. En los poemas presentados arriba, las Carmelitas franco-belgas rinden homenaje al santo y evocan su capacidad literaria, pero aparentemente sin entrar en el espacio poético sanjuanista como lo habían hecho Cecilia del Nacimiento y María de San Alberto, quienes imitaron tan estrechamente el léxico y la estructura de la Noche oscura. Ahora, con la ayuda de un texto "intermedio", se demostrará que por lo menos una de las poetas del Carmelo descalzo francés también habitó este espacio literario sanjuanista, imitando el Cántico espiritual de san Juan sin salir del marco poético teresiano.

33 "Pour la fête de notre père Saint Jean de la Croix", Poema 2, estrofa 3.

${ }^{34}$ Marie-Joseph de Jésus, "Couplets composés à l'occasion du jubilé de 250 de la mort de notre père St Jean de la Croix", estrofa 1.

\section{Homenaje e imitación}

Por su (ya citada) primera estrofa, el primero de los poemas de la serie de los archivos de Pontoise parece ser, como los demás, un poema que celebra a san Juan sin necesariamente imitar su poesía:

Chantons mes sœurs aujourd'hui la mémoire

du St trépas de l'éclatante gloire

que mérita le grand Jean de la Croix

en son honneur réunissons nos voix

réunissons nos voix. ${ }^{35}$

Pero en la segunda estrofa, la autora compara a san Juan a una "paloma”, y las imágenes empiezan a sugerir, aunque no de forma explícita, el léxico sanjuanista:

Vous le prendriez pour la chaste colombe

Qui fend les airs et qui jamais ne tombe

Toujours brûlant d'un tout céleste feu

Il vole droit au cœur même de Dieu

Au cœur même de Dieu. ${ }^{36}$

De manera muy general, las referencias en esta estrofa a la paloma y a su vuelo podrían recordar la decimotercera estrofa del Cántico espiritual de san Juan:

¡Apártalos, Amado,

que voy de buelo! Buélvete, paloma,

que el ciervo vulnerado

por el otero asoma

al ayre de tu buelo, y fresco toma.

(Cántico espiritual, estrofa 13)

En la tercera estrofa del poema francés, san Juan sigue representado por la paloma, y otra vez surge una sutil afinidad entre el poema francés y el cántico sanjuanista. El nido solitario de la paloma se cita como el lugar en que san Juan queda herido del amor de Cristo:

35 "Pour la fête de notre père Saint Jean de la Croix", Poema 1, estrofa 1.

36 "Pour la fête de notre père Saint Jean de la Croix", Poema 1, estrofa 2.

UNED. REI, 3 (2015), pp. 45-80

ISSN 2340-9029 
Son nid cétait la chère solitude

Il y vivait en grande quiétude

De son amour Jésus l'avait blessé :

De son amour Jean le tenait pressé

Jean le tenait pressé. ${ }^{37}$

En la estrofa 35 del Cántico espiritual de san Juan, encontramos el mismo nido, la misma soledad y también el herido divino:

\section{En soledad vivía}

y en soledad a puesto ya su nido,

y en soledad la guía

a solas su querido,

también en soledad de amor herido.

(Cántico espiritual, estrofa 35)

La presencia de estos elementos en las segunda y tercera estrofas del poema francés sugiere que la autora francesa ha entrado, aunque algo tímidamente, en el espacio poético sanjuanista. Pero ayuda a confirmarlo la lectura de otro texto: la traducción del Cántico espiritual del Carmelita francés Cyprien de la Nativité de la Vierge (1605-1680), que parece establecer una conexión más definitiva entre el poema francés y el poema original de san Juan ${ }^{38}$. La estrofa 35 de la traducción del padre Cyprien:

En solitude elle vivait

Son nid est dans la solitude ;

En solitude la pourvoit

L'Auteur seul de la quiétude :

Lui qu'un même amour a pressé

Et en solitude blessé. ${ }^{39}$

37 "Pour la fête de notre père Saint Jean de la Croix", Poema 1, estrofa 3.

${ }^{38}$ Un traductor y poeta prolífico, Cyprien de le Nativité de la Vierge fue redescubierto en el siglo XX por el poeta francés Paul Valéry, quien escribió en un prefacio a la edición de 1941 de Les Cantiques spirituels de Saint Jean de la Croix: "Je propose aux amateurs des beautés de notre langage de considérer désormais l'un des plus parfaits poètes de France dans le R.P. Cyprien de la Nativité de la Vierge" (Valéry, 1941). Las traducciones del padre Cyprien, en particular sus traducciones de los poemas de san Juan y de santa Teresa, aparecen en varias antologías de poesía francesa.

${ }^{39}$ Cyprien de la Nativité de la Vierge (1665: 253).
En el poema de los archivos de Pontoise y también en la traducción del padre Cyprien, los términos solitude-quiétude se encuentran en posición de rima y, aún más importante, los términos pressé-blessé, así como la expresión presser d’amour, acción ejercitada sobre Dios/ Cristo en los dos poemas franceses..$^{40}$ Esta expresión aparece en los escritos de varios autores franceses, entre ellos san Francisco de Sales, Jeanne Guyon y el poeta Amadis Jamyn ${ }^{41}$. Pero no hay ni en el Cántico espiritual original de san Juan ni en las otras traducciones francesas de la época del poema ninguna expresión parecida ${ }^{42}$, lo cual sugiere que el poema del archivo de Pontoise es una imitación de una traducción, muy probablemente la de Cyprien de la Nativité de la Vierge. Un análisis más profundo de los tres poemas lo confirmará.

${ }^{40}$ Aunque el enfoque de este análisis es el léxico sanjuanista y su presentación en primer plano gracias a la rima, también se podría mencionar el uso de la rima interna, una de las características más remarcables de la poesía de san Juan en su versión original. En el poema de Pontoise que imita el Cántico espiritual, la rima interna también es muy frecuente, como se ve en las estrofas citadas arriba, por ejemplo en el verso Il y vivait en grande solitude. Curiosamente, en la traducción del Cántico espiritual del padre Cyprien de la Nativité de la Vierge, la rima interna es casi inexistente. Aunque sería difícil demostrarlo de manera definitiva, es interesante considerar la posibilidad de que la autora del poema de Pontoise conociera el texto original de san Juan, y que la versión original del texto sanjuanista tuviera una influencia en el proceso de composición del poema carmelitano francés.

${ }^{41}$ En el séptimo libro de su Traité de l'amour de Dieu, san Francisco de Sales escribe, "rien ne presse tant le cœur de l'homme que l'amour" (1637: 255); en su explicación de los Hechos de los Apóstoles, Jeanne Guyon escribe sobre el martirio de san Esteban, "O Étienne!...que vous êtes digne d'envie, \& qu'il serait doux à un cœur blessé \& pressé d'amour d'éprouver la même fortune !" (1790: 23); en una oda de su colección Oriane, Amadis Jamyn escribe:

$$
\begin{aligned}
& \text { Lors je m’écarte en un bois solitaire, } \\
& \text { Pressé d’amour qui sans trêve m’assaillait } \\
& \text { Mon faible cœur : ma raison au contraire } \\
& \text { Pour le défendre en vain se travaillait. }
\end{aligned}
$$$$
\text { (1978: 17) }
$$

${ }^{42}$ En 1828, el Jesuita Guillaume François Berthier publicó una traducción al francés de las obras de san Juan en que tradujo los versos del santo en prosa, sin métrica ni rima. En esta traducción, la expresión pressé/presser d’amour no aparece. Tampoco aparece esta expresión en las traducciones previas del Jesuita Jean Maillard (1694), y René Gaultier (1622).

UNED. REI, 3 (2015), pp. 45-80

ISSN 2340-9029 
En la cuarta estrofa del poema del archivo de Pontoise, el léxico y las imágenes son parecidos a los de la estrofa 26 del Cántico espiritual, aunque con perspectivas narrativas diferentes:

Avec Jésus y conversant sans peine

Il découvrait dans cette vaste plaine

Les hauts secrets de sa divinité

Les doux secrets de son humanité

De son humanité. ${ }^{43}$

En la interior bodega

de mi Amado beví, y, quando salía

por toda aquesta bega,

ya cosa no sabía,

y el ganado perdí que antes seguía.

(Cántico espiritual, estrofa 26)

Una lectura de estas dos estrofas con la traducción del padre Cyprien como texto intermedio ayuda a confirmar la relación entre ellas:

Dans le cellier plus retiré

De mon ami j’ai bu sans peine,

Et par ce nectar désiré

Surprise sortant en la plaine,

J'oubliai ce que je savais,

Jusqu'au troupeau que je suivais. ${ }^{44}$

En la traducción del padre Cyprien, los términos sans peine y plaine en posición de rima son los mismos que se hallan, también en posición de rima, en el poema del archivo de Pontoise. Esto ayuda a confirmar que, por medio de una traducción, la autora carmelitana francesa se adentró en el espacio poético sanjuanista, copiando su lenguaje o por lo menos el lenguaje de su traductor.

\footnotetext{
43 "Pour la fête de notre père Saint Jean de la Croix", Poema 1, estrofa 4.
}

${ }^{44}$ Cyprien de la Nativité de la Vierge (1665: 251).
En la quinta estrofa del poema del archivo de Pontoise, la autora que antes contaba la historia de la "paloma" a sus hermanas ahora se dirige a Dios, y otra vez hay una correspondencia general entre su poema, el Cántico espiritual de san Juan y la traducción de Cyprien de la Vierge:

De quel amour embrasez-vous son âme

Divin esprit par votre sainte flamme!

Les fruits divins naissaient avec les fleurs:

Son cœur sans cesse exhalait vos odeurs

Exhalait vos odeurs. ${ }^{45}$

Detente, cierço muerto;

ven, austro, que recuerdas los amores,

aspira por mi huerto,

y corran tus olores,

y pacerá el Amado entre las flores.

(Cántico espiritual, estrofa 17)

Morte brise arrête ton cours :

Lève-t-y, ô Sud, qui réveilles

Par les souffles les saints amours,

Fais par mon jardin tes merveilles;

Car en répandant ses odeurs,

Mon ami paîtra dans les fleurs. ${ }^{46}$

En los últimos versos de las tres estrofas citadas arriba, los términos fleurs-odeurs y "flores-olores" corresponden, así como las frases exhalait vos odeurs-"corran tus olores"-répandant ses odeurs. De manera semejante, la sexta estrofa del poema del archivo de Pontoise, en que la autora evoca el jardín donde el amado y la amada se reúnen, corresponde generalmente a la estrofa 22 del Cántico espiritual, y aún más estrechamente a la estrofa 28 de la traducción de Cyprien de la Nativité de la Vierge:

45 "Pour la fête de notre père Saint Jean de la Croix", Poema 1, estrofa 5.

${ }^{46}$ Cyprien de la Nativité de la Vierge (1665: 252).

UNED. REI, 3 (2015), pp. 45-80

ISSN 2340-9029 
Dans ce jardin vous faisiez vos délices ;

C'est pour vous seul qu'étaient tous ses services

De vous aimer c'était la passion

De vous servir la seule ambition

La seule ambition. ${ }^{47}$

Entrado se á la esposa

en el ameno huerto desseado,

y a su sabor reposa,

el cuello reclinado

sobre los dulces braços del Amado.

(Cántico espiritual, estrofa 22)

L'Épouse est entrée au jardin,

Ce beau paradis de délices :

Et repose en l'époux divin,

Pour lequel sont tous ses services,

Mettant son col dessus ses bras,

Où elle trouve mille appas. ${ }^{48}$

Mientras que el entorno general del huerto-jardin sugiere la conexión entre el poema del archivo de Pontoise y el Cántico de san Juan, la traducción del padre Cyprien la confirma con los términos délicesservices en posición de rima en los dos poemas franceses y sobre todo con la frase tous ses services, que aparece en la traducción de Cyprien y que se reproduce exactamente en el poema del archivo carmelitano.

En la séptima estrofa del poema del archivo de Pontoise, un grupo semejante de términos establece la conexión entre los textos de la autora carmelitana, Juan de la Cruz y su traductor. Ahora la carmelita se dirige directamente al santo, aparentemente siempre representado por la paloma:

Prenez grand saint un vert rameau d'olive

Partez, volez, quittez la triste rive :

On vous attend dans le lieu de repos :

47 "Pour la fête de notre père Saint Jean de la Croix", Poema 1, estrofa 6.

${ }^{48}$ Cyprien de la Nativité de la Vierge (1665: 252).

UNED. REI, 3 (2015), pp. 45-80

ISSN 2340-9029
Déjà du ciel résonnent les échos

Résonnent les échos. ${ }^{49}$

La blanca palomica

al arca con el ramo se ha tornado,

y ya la tortolica

al socio desseado

en las riberas verdes a hallado.

(Cántico espiritual, estrofa 34)

La Blanche Colombe en ce jour

Avec son vert rameau d'olive,

Est dedans l'Arche de retour;

Là sur la verdoyante rive

La Tourtre trouve retiré

Son pair qu'elle avait désiré. ${ }^{50}$

En este caso, los términos rameau-"ramo" y rive-"ribera" sirven para establecer la conexión general entre el poema del archivo de Pontoise y el Cántico de san Juan, y otra vez una frase común a los dos textos franceses la confirma: el vert rameau d'olive del segundo verso de la traducción del padre Cyprien, que se halla reproducido en el primer verso del poema de la autora carmelitana.

La conclusión del poema del archivo de Pontoise consiste en tres estrofas en las que la autora retoma el tono de alabanza general que caracteriza los otros poemas de la serie, dejando el lenguaje sanjuanista y así saliendo del espacio poético del santo. Pero el "corazón" de este poema (las estrofas 2 a 7 que se citan y comentan arriba) tiene el sello de san Juan de la Cruz y de su Cántico espiritual, y representa no solo el deseo de imitación poética que se puede detectar en los poemas que lamentan la falta de "voz y pluma" adecuadas para elogiar al santo, sino también la realización de este deseo, en versos claramente sanjuanistas pero siempre de estilo teresiano. Una parte importante de la singularidad de este poema consiste precisamente en

49 "Pour la fête de notre père Saint Jean de la Croix", Poema 1, estrofa 7.

${ }^{50}$ Cyprien de la Nativité de la Vierge (1665: 253).

UNED. REI, 3 (2015), pp. 45-80

ISSN 2340-9029 
esta combinación teresiana-sanjuanista, en la imitación de san Juan dentro de una estructura teresiana, no de un poema culto, sino de una canción popular "a lo divino". Mientras que las carmelitas españolas Cecilia del Nacimiento y María de San Alberto habían copiado cada aspecto de la Noche oscura de san Juan (tema, léxico y estructura), la imitación de san Juan en el texto francés es menos evidente, pero quizás más típicamente teresiana, quedándose dentro de los límites estructurales de un poema cantado de estilo popular.

Cabe mencionar otro aspecto novedoso de esta poesía híbrida: la fusión de poesía encomiástica y poesía imitativa. Si los poemas de Cecilia del Nacimiento y María de san Alberto sobre la noche sanjuanista copian el estilo y el lenguaje de san Juan, todos los poemas franco-belgas que rinden homenaje al santo evitan cualquier imitación y mantienen un carácter puramente encomiástico, con la excepción del poema que imita el Cántico espiritual, presentado y analizado arriba. Juntando poesía encomiástica y poesía imitativa, esta composición excepcional representa un tipo de término medios literario entre los poemas de las Carmelitas españolas y los demás poemas franco-belgas.

Finalmente, merece compararse el uso de la alegoría en el Cántico espiritual de San Juan, los poemas de Cecilia del Nacimiento y María de san Alberto y el poema de Pontoise que imita el cántico sanjuanista. En su artículo "Could Women Write Mystical Poetry?", Alison Weber (2009) demuestra que en los poemas de Cecilia del Nacimiento y María de San Alberto, las Carmelitas españolas "revelan" lo que san Juan deja oculto en su poema Noche oscura, es decir, la identidad de la "amada" y el "amado" cuya unión amorosa se evoca en el poema. Mientras que san Juan deja la identidad alegórica de sus protagonistas oculta detrás de los pronombres "él" y "yo" y los términos "amada" y "amado", las Carmelitas españolas desatan el nudo alegórico sanjuanista, copiando el lenguaje del santo, pero incorporando referencias explícitas a Dios y a Cristo. En esto, la autora del poema de Pontoise sigue el ejemplo de sus hermanas Cecilia y María (quizás sin saberlo), imitando el lenguaje de san Juan pero di- solviendo la alegoría que también caracteriza el Cántico espiritual, en que la narradora y el "Amado" mantienen identidades aparentemente humanas. Transformando a san Juan en una paloma que conversa con Jesús, la autora del poema de Pontoise efectúa una desalegorización de su fuente de inspiración, quizás por el mismo motivo. Como lo explica Weber (2009: 200-201):

I have been arguing that the mystical poems by María de san Alberto and Cecilia del Nacimiento demonstrate that Discalced Carmelite women "could" (that is "sabían") write mystical poetry: they had the necessary competence in poetic and allegorical codes, and they enjoyed sufficient trust in their audience intramuros to attempt such an endeavor. [...] However, they could not ("no podían") write mystical poetry with the same lyrical freedom as their Carmelite brother. If Juan de la Cruz felt compelled to protect himself from external censorship by writing manifestly orthodox allegorical prose commentaries, Carmelite women had to contend with external and internal constraints. [...] Like San Juan, they embraced allegory as a protective cover for mysticism's erotic vocabulary and as an expressive medium in its own right. Unlike the Carmelite friar, the nuns could not sever allegory from lyrical fiction.

Imitando la poesía de san Juan, pero siempre con la protección de un lenguaje explícitamente religioso, la autora del poema de Pontoise parece haber "pecado de precavida", por así decirlo, como sus antepasadas españolas.

\section{Post scriptum: imitación sanjuanista francesa}

Desde la primera publicación del Cántico espiritual en Francia, en la traducción de René Gaultier en 1622 - y cabe recordar que esta era la primera vez que el poema había sido publicado en cualquier lengua, ya que hasta esa fecha había sido excluido de las ediciones de 
las obras de san Juan en castellano ${ }^{51}$ - san Juan de la Cruz siempre ha tenido una presencia y una influencia importantes en Francia. Sus obras completas fueron traducidas múltiples veces en el siglo XVII ${ }^{52}$ y nunca han faltado nuevas ediciones de sus escritos. El santo también ha sido el objeto de una intensa atención académica en Francia. En los estudios de Jean Baruzi, André Bord, Jean Orcibal, Bartolomé Bennassar y muchos más, se ha demostrado que el pensamiento y los escritos sanjuanistas han sido de gran interés en el ámbito intelectual francés ${ }^{53}$. Por su parte, los artistas franceses también se han interesado por san Juan: en los años 1960, el pintor Alfred Manessier produjo una serie de doce cuadros inspirados en el Cántico espiritual, y en 1968 el coreógrafo Maurice Béjart realizó una pieza basada en la Noche oscura de san Juan, prueba de que los textos sanjuanistas y su espíritu llegaran a tener un impacto en el mundo artístico en Francia (y en Bélgica, donde trabajó Béjart durante 27 años) ${ }^{54}$. Es más, por lo menos un poeta francés ha sentido esta influencia: en 1963, Louis Aragón (1963: 415-416) publicó la colección Le Fou d'Elsa, que contiene un poema titulado simplemente "Jean de la Croix":

Il dit que l'âme est une lampe

Et d'elle ne vient point le feu

Il faut que quelqu'un le lui donne

La flamme d'amour est de Dieu.

Jean de la Croix je te demande

Non des mots pour l'Inquisiteur

Mais d'éclairer la Nuit obscure

De ta lumière

Jean de la Croix.

\footnotetext{
${ }^{51}$ El poema se publicó en castellano por primera vez en 1627, en una edición de la obras de san Juan hecha en Bruselas.

${ }^{52}$ En las traducciones de René Gaultier, Cyprien de la Nativité de la Vierge y Jean Maillard (ver Referencias bibliográficas).

${ }^{53}$ Baruzi (1924); Bord (1993); Orcibal (1966); Bennassar (1993: 99-117).

${ }^{54}$ Manessier (1972) y Béjart (1968).
}

Con sus referencias a los poemas "Llama de amor viva" (Flamme d'amour) y "Noche oscura" (Nuit obscure), este poema, como los poemas de las carmelitas españolas, francesas y belgas a los que se hace referencia en este estudio, infunde el espíritu de Juan de la Cruz. Pero como la mayoría de los poemas franco-belgas que aquí se presentan, el de Aragón es más un caso de evocación que un caso de imitación: el poeta francés nombra a san Juan y hasta menciona algunos de sus escritos, pero no llega a incorporar ningún lenguaje propiamente sanjuanista o a imitar los poemas del santo de manera temática. Pero para la autora del poema del archivo de Pontoise, cuyo "corazón" manifiesta tanta influencia del Cántico espiritual (y sobre todo de su traducción francesa), la celebración del gran poeta fue más allá de un homenaje en verso, hasta el punto de imitar detalles del lenguaje poético del santo, en un acto literario que, por lo que yo sé, no tenía precedente y tampoco se ha repetido desde entonces en Francia. Como recomienda la autora del segundo poema de la serie del archivo de Pontoise:

Puisons dans son livre divin

Les trésors qu'il renferme

Puisons dans son livre divin

Nous parviendrons au terme..$^{55}$

(Poema 2, estrofa 7)

Por lo visto, una de las carmelitas de Francia aceptó este consejo y, como sus antepasadas españolas Cecilia del Nacimiento y María de san Alberto, quienes obtuvieron tanta inspiración de la noche sanjuanista, la carmelita francesa aprovechó el canto de su padre espiritual, elogiándolo con su propio lenguaje, y creando quizás la única imitación literaria francesa de su Cántico espiritual que se conoce.

55 "Pour la fête de notre père Saint Jean de la Croix", Poema 2, estrofa 7.

UNED. REI, 3 (2015), pp. 45-80

ISSN 2340-9029 


\section{Conclusiones}

Los poemas que se presentan en este estudio demuestran que siglos después de la fundación del Carmelo descalzo español, tanto la tradición teresiana como la memoria y la poesía de san Juan de la Cruz seguían vivas para las Carmelitas franco-belgas de los siglos XVIII y XIX. Estos textos también demuestran que la manera en que estas carmelitas celebraron a san Juan fue a la vez sanjuanista y teresiana. En un sentido, toda la poesía conventual del Carmelo descalzo es teresiana, dada la insistencia de Teresa en la composición de versos en los conventos que fundó. Dicho esto, la serie de poemas que se presenta aquí es excepcional, un "ciclo sanjuanista" dentro de una tradición teresiana en que las hijas franco-belgas de Teresa de Jesús y Juan de la Cruz celebraron a su padre usando el estilo poético de su madre, y en un caso fusionando el estilo teresiano y la poesía sanjuanista. Finalmente, esta poesía híbrida parece ser única: como se ha visto, existen poemas conventuales carmelitanos que imitan la poesía de san Juan, pero son composiciones cultas que se salen en cierto sentido del marco poético teresiano. Mientras que la imitación de la Noche oscura de san Juan en las "Liras" de Cecilia del Nacimiento y María de San Alberto es casi total, en la adaptación francesa del Cántico espiritual que se presenta aquí, Teresa y Juan están presentes en igual medida: Teresa en la estructura de un poema "a lo divino", y Juan en el léxico y las imágenes de su más famoso poema. Quizás aún más que en España, al norte de los Pirineos la poesía teresiana y la poesía sanjuanista convergieron, en los poemas de las hijas del "père de famille" y de "la grande Thérèse".

Recibido: $22 / 06 / 2015$

Aceptado: 26/08/2015

\section{Referencias bibliográficas}

Álvarez Pellitero, Ana María (1983), "Cancionero del Carmelo de Medina del Campo", en Teófanes Egido Martínez, Víctor García de la Concha \& Olegario González de Cardedal eds., Actas del Congreso Internacional Teresiano, 4-7 octubre, 1982, Salamanca: Universidad de Salamanca, t. II, pp. 525-543.

Aragon, Louis (1963), Le Fou d'Elsa: poème, Paris: Gallimard.

Arenal, Electa y Stacey Schlau (2010), Untold Sisters: Hispanic Nuns in Their Own Works, Albuquerque (New Mexico): University of New Mexico Press.

Baruzi, Jean (1924), Saint Jean de la Croix et le problème de l'expérience mystique, Evreux: impr. Ch. Hérissey.

Béjart, Maurice (1968), La Nuit obscure, http://www.maurice-bejart. $\mathrm{ch} / \mathrm{chrono} / 02 . \mathrm{html}$

Bennassar, Bartolomé (1993), "Recepción y audiencia de Juan de la Cruz en Francia", en Teófanes Egido coord., Actas del Congreso Internacional Sanjuanista: Ávila, 23-28 de septiembre de 1991, Valladolid: Junta de Castilla y León, Consejería de Cultura y Turismo, vol. 2, pp. 99-117.

Béraud, Antoine y P. Dufey (1828), Dictionnaire historique de Paris, Paris: Barba, 1828.

Bord, André (1993), Jean de la Croix en France, Paris: Beauchesne.

Cecilia del Nacimiento (1971), Obras completas, ed. J. M. Díaz Cerón, Madrid: Editorial de la Espiritualidad.

François de Sales (santo) (1637), Les Euvres de Messire François de Sales, Toulouse: Pierre Bosc, \& Arnavd Colomiez.

García de la Concha, Víctor (1978), El arte literario de Santa Teresa, Barcelona: Ariel.

García de la Concha, Víctor y Ana María Álvarez Pellitero (1982), Libro de romances y coplas del Carmelo de Valladolid (c.1590-1609), Salamanca: Consejo General de Castilla y León, 2 vols.

UNED. REI, 3 (2015), pp. 45-80

ISSN 2340-9029 
Guyon, Jeanne (1790), La Sainte Bible: avec des explications \& réflexions qui regardent la vie intérieure, Paris: Chez les Libraires associés.

Hanna, Daniel (2015a), "The Poetic Habit: Verse and Vestment in Spanish and French Carmel", Early Modern Women: An Interdisciplinary Journal, 9, 2, Spring, pp. 39-64.

--- $(2015$ b), "Un trait thérésien: French Carmelite Poetry in the Tradition of Teresa of Ávila", Bulletin of Spanish Studies, on line, DOI: 10.1080/14753820.2015.1105558 [publicación provisional] http:// www.tandfonline.com/doi/full/10.1080/14753820.2015.1105558

--- (en prensa), "Defending Divinity: A Teresian Carmelite Responds to Ernest Renan's Vie de Jésus", Women in French Studies.

Jamyn, Amadis y Samuel M. Carrington (1978), Les œuvres poétiques: livres II, III et IV (1575), Genève: Droz.

Jean de la Croix (santo) (1622), Cantique d'amour divin entre JésusChrist et l'âme dévote, trad. René Gaultier, Paris: A. Taupinart.

--- (1665), Les Euvres spirituelles du B. P. Jean de la Croix, trad. Cyprien de la Nativité de la Vierge, Paris: E. et J. Couterot.

--- (1694), Les Euvres spirituelles du Bienheureux Jean de la Croix, trad. Jean Maillard, Paris: L. Guérin.

--- (1828), Les Euvres spirituelles du Bienheureux Jean de la Croix, trad. François Berthier, Avignon: L. Aubanel.

--- y Paul Valéry (1941), Les Cantiques spirituels de Saint Jean de la Croix, Paris: L. Rouart et fils.

Juan de la Cruz (santo) (1627), Declaración de las canciones, que tratan del ejercicio de amor entre el alma, y el Esposo Cristo, Bruselas: Godofredo Schoevarts.

---- (2006), Poesía, ed. Domingo Ynduráin, Madrid: Cátedra.

Madeleine de Saint-Joseph (1965), Lettres spirituelles de Madeleine de Saint-Joseph. Ed. Pierre Sérouet, Paris: Desclée de Brouwer.
Manessier, Alfred (1972), Cantiques spirituels de Saint Jean de la Croix, 12 tapisseries tissées par l'atelier Plasse-Le Caisne. 26 novembre 1972-14, janvier 1973, Musées De Metz, Metz: Editions des Musées de Metz.

María de San Alberto y Stacey Schlau (1998), Viva al siglo, muerta al mundo: Selected Works by/Obras escogidas de María de San Alberto (1568-1640), New Orleans: University Press of the South.

María de San José (2002), Book for the Hour of Recreation, intr. Alison Weber, trad. Amanda Powell, Chicago: University of Chicago Press.

Orcibal, Jean (1966), Saint Jean de la Croix et les mystiques rhénoflamands, Bruges: Desclée de Brouwer.

Orozco Díaz, Emilio (1994), Estudios sobre san Juan de la Cruz y la mística del barroco, Granada: Universidad de Granada, 2 vols.

Pérez, Joseph (2007), Teresa de Ávila y la España de su tiempo, Madrid: Algaba Ediciones.

Rhodes, Elizabeth (2009), "Gender in the Night: Juan de la Cruz and Cecilia del Nacimiento", en Julián Olivares ed., Studies on Women's Poetry of the Golden Age, Woodbridge (UK): Tamesis, pp. 202-217.

Scribe, Eugène (1824), Le Dîner sur l'herbe, Paris: Pollet.

Sesé, Bernard (2005), "Poética de 'nada' según san Juan de la Cruz", en Christophe Couderc y Benoît Pellistrandi eds., Por discreto y por amigo: Mélanges offerts à Jean Canavaggio, Madrid: Casa de Velázquez, pp. 439-452.

Teresa de Jesús (santa) (2006), Obras completas, ed. Efrén de la Madre de Dios y Otger Steggink, Madrid: Biblioteca de Autores Cristianos.

Toft, Evelyn (2000), "Cecilia del Nacimiento: Mystic in the Tradition of John of the Cross", en Robert Boenig ed., The Mystical Gesture: Essays on Medieval and Early Modern Spiritual Culture in Honor of Mary E. Giles, Aldershot, Hampshire, England: Ashgate, pp. 169-184.

--- (2001), "Joy in the Presence of the Bridegroom: The Contemplative Poetry of Cecilia del Nacimiento", Studia mystica 22, pp. 83-96.

UNED. REI, 3 (2015), pp. 45-80

ISSN 2340-9029 
--- (2010), "Cecilia del Nacimiento: Second-Generation Mystic of the Carmelite Reform", en A New Companion to Hispanic Mysticism, Leiden: Brill, pp. 231-252.

Torres Sánchez, Concha (2000), La clausura imposible, Madrid: Asociación Cultural Al-Mudayna.

Weaver, Elissa (2002), Convent Theatre in Early Modern Italy: Spiritual Fun and Learning for Women, Cambridge: Cambridge University Press.

Weber, Alison (1990), Teresa of Avila and the Rhetoric of Femininity, Princeton (New Jersey): Princeton University Press.

--- (2009), "Could Women Write Mystical Poetry? The Literary Daughters of Juan de la Cruz", en Julián Olivares ed., Studies on Women's Poetry of the Golden Age, Woodbridge (UK): Tamesis, pp. 185201.

Wilson, Christopher C. (2007), "Masculinity Restored: The Visual Shaping of John of the Cross", Archive for Reformation History, 98, pp. 134-166. 